\title{
Caracterización y evolución del empleo asalariado formal creado por empresas del sector privado en la Provincia de Santa Fe (2007-2013)
}

Characterization and evolution of formal employment created by private sector companies in Santa Fe (2007-2013)

\author{
Martín Carné* \\ Facultad de Ciencia Política y Relaciones \\ Internacionales, Universidad Nacional de \\ Rosario, Argentina. Becario Postdoctoral \\ del Consejo Nacional de Investigaciones \\ Científicas y Técnicas. \\ E-mail: carnetes@hotmail.com
}

\section{Resumen}

Sirviéndose de una novedosa — y aún poco explorada — fuente de información ofrecida por el Ministerio de Trabajo y Seguridad Social de la Provincia de Santa Fe (constituida a partir de registros administrativos del Sistema Integrado Previsional Argentino), el presente trabajo tiene por objetivo caracterizar el segmento más grande (y muchas veces menos conocido) de ocupados: el de asalariados formales (con descuento jubilatorio) registrados por empresas del sector privado (en este caso, empresas con domicilio fiscal en dicha provincia). La tarea se plantea tanto para el nivel agregado provincial, las cinco regiones en que se organiza administrativamente el territorio santafesino y los aglomerados Gran Rosario y Gran Santa Fe a partir de las variables tamaño y actividad económica

Palabras clave

- asalariados formales

- provincia de Santa Fe

- Sistema de consultas de empleo privado registrado de la empresa empleadora. Asimismo, analiza su evolución durante el período 2007-2013, años en los que, según algunos economistas, referentes políticos y comunicadores, la economía argentina habría perdido capacidad de generar empleo genuino en el sector privado. 


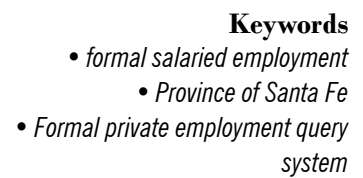

Keywords - Province of Santa Fe system

\begin{abstract}
Drawing upon a new —and still little explored — source of information offered by the Ministry of Labour and Social Security of the Province of Santa Fe (source formed from administrative records of the Argentine Integrated Pension System), this paper aims to characterize the larger (and often less known) segment of workers: the salaried employees of private companies (in this case, companies with tax residence in that province). The task arises for both the provincial aggregate level, the five regions that administratively organize the Santa Fe territory and Gran Rosario and Gran Santa Fe agglomerates from the variables size and economic activity of the employing company. It also analyzes its evolution during the period 2007-2013, years in which, according to some economists, politicians and journalists, Argentine economy would have lost capacity to generate genuine occupations in the private sector.
\end{abstract}

\section{Introducción}

Los últimos datos de la Encuesta Permanente de Hogares (EPH) confirman — para el total de aglomerados urbanos relevados - que aproximadamente tres de cada cuatro ocupados son asalariados. Este hecho habilita subrayar y/o problematizar dos cuestiones. La primera se vincula con la importancia que guardan los rasgos que caracterizan tal categoría dado que ellos refieren al $75 \%$ de los ocupados, algo así como el 30\% del total poblacional. La segunda, es propia de la herramienta de medición: aún con la amplitud de temas que releva (reformulados en 2003) y aplicándose en treinta y un aglomerados urbanos (los que representan casi el $70 \%$ de la población total del país), la EPH es un instrumento muestral de recolección de datos que deja en un cono de sombras los atributos de una considerable franja de la población. En este sentido, por ejemplo, los analistas pueden aproximarse a la realidad ocupacional de la provincia de Santa Fe a partir de lo observado sólo en los aglomerados Gran Rosario (GR) y Gran Santa Fe (GSF) ya que recién desde 2010 la Encuesta Anual de Hogares Urbanos
(EAHU) ofrece información correspondiente a localidades de dos mil y más habitantes (agregadas bajo la etiqueta «Resto de Santa Fe»).

Para reforzar los aportes de estas fuentes y ahondar con mayor detalle en la situación particular de los asalariados con descuento jubilatorio, formales, registrados por empresas o personas físicas del sector privado provincial, el Observatorio Laboral del Ministerio de Trabajo y Seguridad Social de la Provincia de Santa Fe (MTySS) permite, desde tiempo atrás a la fecha, disponer (vía sistema de consultas online) de datos provenientes del Sistema Integrado Previsional Argentino (SIPA), el cual se constituye - en parte - sobre la base de declaraciones juradas de seguridad social que los empleadores mensualmente presentan ante la Administración Federal de Ingresos Públicos (AFIP). Esta plataforma brindada por el MTySS ayuda a conocer a nivel agregado o para cada localidad, departamento, aglomerado y región del territorio provincial el nivel cuantitativo de asalariados y empresas privadas registradas con domicilio fiscal en dicho territorio y atributos tales como el tipo de actividad económica 